\title{
Inoculação das sementes e adubações nitrogenada e molíbdica do feijoeiro-comum, em Rolim de Moura, RO
}

\author{
Franciele Caroline de Assis VALADÃO ${ }^{1}$, Adriano JAKELAITIS², Lenita Aparecida CONUS³, Lucas \\ BORCHARTT $^{4}$, Abdias Alves de OLIVEIRA5 ${ }^{5}$, Daniel Dias VALADÃO JUNIOR ${ }^{6}$
}

\begin{abstract}
RESUMO
O objetivo deste estudo foi avaliar o desempenho do feijoeiro-comum (Phaseolus vulgaris L) em função da inoculação de sementes com Rhizobium tropici e das adubaçóes nitrogenada e molibdica. Utilizou-se o delineamento em blocos casualizados, com quatro repetiçóes, em arranjo fatorial $2 \times 2 \times 2$, constituindo-se das combinaçóes de ausência e presença de inoculação de sementes, da adubação molíbdica e da adubação nitrogenada. A inoculação das sementes foi imediatamente antes da semeadura com inoculante turfoso composto da estirpe CIAT 899 (SEMIA 4077); a adubação nitrogenada foi na semeadura (10 kg.ha-1) e em cobertura (50 kg.ha-1), quando as plantas apresentaram a terceira folha trifoliolada expandida e o molibdênio (Mo) foi aplicado em pulverizaçáo foliar na dose de 60 g.ha ${ }^{-1}$. Não foram observados efeitos dos tratamentos para a massa seca de raízes e o número de vagens por planta. A adubação nitrogenada reduziu a nodulaçáo nos feijoeiros. Todavia, com a adubaçáo nitrogenada foi verificado incremento na altura e na massa seca da parte aérea dos feijoeiros. Grãos de feijão mais pesados foram observados em feijoeiros adubados com N na ausência de Mo. As interaçóes entre adubação nitrogenada e molibdica com inoculação de sementes afetaram, também, o teor de $\mathrm{N}$ foliar e o número de grãos por vagem $\mathrm{A}$ inoculação de sementes proporcionou nos feijoeiros rendimentos de grãos semelhantes aos fertilizados com $\mathrm{N}$.
\end{abstract}

PalaVRaS-ChaVE: Phaseolus vulgaris, Rhizobium tropici, fixação biológica de nitrogênio, molibdênio.

\section{Seeds inoculation and nitrogen and molybdenum fertilization of common bean in Rolim de Moura, RO}

\section{ABSTRACT}

The aim of this study was to evaluate the effects of seed inoculation with Rhizobium tropici and nitrogen and molybdenum fertilization on the performance of the common-bean (Phaseolus vulgaris L.). A complete randomized block design with four replicates was used, in a factorial arrangement $2 \times 2 \times 2$, with the combinations of absence and presence of seed inoculation and nitrogen $(\mathrm{N})$ and molybdenum (Mo) fertilization. Seeds inoculation was just before sowing with a peat inoculante composed by the strain CIAT 899 (SEMIA 4077), N was provided at sowing $\left(10 \mathrm{~kg} \cdot \mathrm{ha}^{-1}\right)$ and coverage $\left(50 \mathrm{~kg} \cdot \mathrm{ha}^{-1}\right)$ when the plants showed the third trifoliate sheet expand and Mo was applied by foliar spraying with $60 \mathrm{~g} \cdot \mathrm{ha}^{-1}$ when plants were at beginning of flowering. No effect of treatments on the dry mass of roots and the number of pods per plant was observed. $\mathrm{N}$ fertilization reduced nodulation of plants, however, $\mathrm{N}$ fertilization lead to an increase in height and dry mass of bean shoots. It was also observed that plants fertilized with $\mathrm{N}$ but in the absence of Mo shoed heavier grains. The interactions between $\mathrm{N}$ and Mo fertilization with inoculation of seed negatively affected the leaf $\mathrm{N}$ content and the number of grains per pod. The inoculation of seed in beans provided grain yields similar to those provided by the treatment with $\mathrm{N}$ fertilization.

KEYWORDS: Phaseolus vulgaris, Rhizobium tropici, biological nitrogen fixation, molybdenum.

\footnotetext{
1 Universidade Federal de Mato Grosso. E-mail: agroassis@gmail.com

2 Universidade Federal de Rondônia. E-mail: ajakelaitis@yahoo.com

${ }^{3}$ Universidade Federal da Grande Dourados. E-mail: le_lora@hotmail.com

${ }^{4}$ Universidade Federal da Paraíba. E-mail: lucasborchartt@yahoo.com.br

${ }^{5}$ E-mail: abdiasalves@yahoo.com

${ }^{6}$ Universidade Federal do Mato Grosso. E-mail: jrdias@ufmt.br
} 


\section{INTRODUÇÃO}

O feijoeiro-comum, Phaseolus vulgaris L, é cultivado por pequenos e grandes produtores, em diversificados sistemas de produção e em todas as regiôes brasileiras, representando uma fonte de renda para os mesmos. Esse grão representa um típico produto de consumo doméstico e de enorme importância na alimentação como fonte de proteína. No Estado de Rondônia, onde a estrutura agrária é propícia ao modelo da agricultura familiar, esta cultura merece destaque pelo notório papel social e econômico que desempenha no meio rural, ao lado de outras culturas como o café, o arroz e o milho.

De acordo com o Instituto Brasileiro de Geografia e Estatística (IBGE), a produção brasileira de feijão em 2007 foi de 3,28 milhóes de toneladas, com rendimento de $859 \mathrm{~kg}^{-h^{-1}}$, sendo considerado baixo. Esse fato decorre da susceptibilidade da cultura à doenças e ao baixo nível tecnológico adotado pela maioria dos produtores. A busca por maiores produtividades com maior rentabilidade passa pela melhoria do solo e da nutriçáo vegetal, em especial da adubaçáo nitrogenada (Malavolta, 2006).

Diante do difícil manejo do $\mathrm{N}$ no agrossistema, a prática da adubação nitrogenada está cada vez mais freqüente nos sistemas produtivos, promovendo conseqüências econômicas e ambientais (Hungria et al., 2001). Todavia, estudos têm sido realizados visando reduzir os custos de produçáo e o impacto ambiental decorrente desta prática, principalmente envolvendo a fixação biológica do nitrogênio (FBN). Assim, a inoculação de sementes com estirpes eficientes de bactérias do gênero Rhizobium é uma alternativa viável para reduzir o uso da adubação de nitrogenada (Pereira et al., 1991).

$\mathrm{Na}$ literatura, vários estudos indicam a possibilidade da substituiçáo da adubação nitrogenada do feijoeiro pela FBN (Mendes et al., 1994, Lemos et al., 2003; Romanini Junior et al., 2007).

No entanto, existe diversidade de resposta à inoculação do feijoeiro, sendo atribuída à alta susceptibilidade da planta aos diversos estresses ambientais, ao ataque de pragas e doenças, e principalmente ao ciclo curto da cultura (Straliotto $\&$ Teixeira, 2000). Oliveira et al. (1996) observaram que rizóbios nativos que nodulam o feijoeiro, mesmo em áreas de primeiro ano de cultivo, são pouco eficientes na FBN, além de dificultar a introdução de estirpes mais eficientes (Vieira et al., 1998).

Por outro lado, é possível por meio do manejo nutricional aumentar a capacidade da FBN nesta cultura, como por exemplo, o fornecimento de micronutrientes. Entre estes, o molibdênio se destaca por ser constituinte estrutural de pelo menos duas enzimas relacionadas ao metabolismo do $\mathrm{N}$, a nitrogenase e a nitrato redutase (Oliveira et al., 1996). Diversos estudos indicam que a adubação molibdica ao feijoeiro resulta em plantas com melhor desenvolvimento e maior produçáo de vagens por planta e de rendimento de grãos

(Berger et al., 1996; Fullin et al., 1999; Ferreira et al., 2003; Fernandes et al. 2005).

Diante do exposto e da carência de pesquisas com o feijoeiro em condiçôes amazônicas, o presente trabalho visou avaliar os efeitos da aplicação de N, do Mo e da inoculaçáo de sementes com Rhizobium tropicci sobre as características agronômicas e de rendimento do feijoeiro-comum, cultivado em Rolim de Moura, RO.

\section{MATERIAL E MÉTODOS}

O experimento foi conduzido no período de dezembro de 2006 a junho de 2007, em área de Latossolo Amarelo distrófico, textura argilosa, pertencente à Fundaçáo Universidade Federal de Rondônia, no município de Rolim de Moura, RO (1 1 ${ }^{\circ} 34^{\prime}$ $\mathrm{S}$ e $\left.61^{\circ} \mathrm{W}\right)$, a $277 \mathrm{~m}$ de altitude. O clima da região, segundo a classificação de Koppen é Tropical-Quente e Úmido Aw, com estaçáo seca bem definida (junho/setembro), temperatura média de $28{ }^{\circ} \mathrm{C}$, precipitaçáo anual de $2.250 \mathrm{~mm}$ e com umidade relativa do ar elevada, oscilando em torno de $85 \%$ (Marialva, 1999).

Antes da instalação do experimento, a área foi cultivada com Brachiaria brizantha como planta de cobertura, que foi dessecada utilizando os herbicidas glyphosate $+2,4-\mathrm{D}$, nas dosagens de $720+319,2$ g.ha ${ }^{-1}$, respectivamente. Posteriormente, foi realizada a coleta de solo na profundidade de $0,20 \mathrm{~m}$ para análises, cujas características químicas e físicas determinadas conforme EMBRAPA (1997) foram: $\mathrm{pH}$ em água $=5,9 ; \mathrm{Al}=0,0 \mathrm{cmol}_{c} \cdot \mathrm{dm}^{-3} ; \mathrm{Ca}=1,5 \mathrm{cmol}_{c} \cdot \mathrm{dm}^{-3} ; \mathrm{Mg}=$ $0,4 \mathrm{cmol}_{c} \cdot \mathrm{dm}^{-3} ; \mathrm{K}=0,15 \mathrm{cmol}_{c} \cdot \mathrm{dm}^{-3} ; \mathrm{P}=4,0 \mathrm{mg} \cdot \mathrm{kg}^{-1}$; valores de argila, silte, areia fina e areia grossa de 40, 12, 18 e 30 dag. $\mathrm{kg}^{-1}$, respectivamente.

O delineamento experimental utilizado foi em blocos ao acaso com oito tratamentos, em arranjo fatorial $2 \times 2 \times 2$ e quatro repetições. Os tratamentos resultaram das combinações de ausência e presença da adubaçáo nitrogenada, aplicada na semeadura e em cobertura, da adubação molíbdica via foliar e da inoculaçáo das sementes com Rhizobium tropici CIAT 899 (SEMIA 4077). Cada parcela foi formada por seis linhas de cinco metros de comprimento espaçadas de meio metro, sendo considerada como área útil as três linhas centrais, com descarte de meio metro das extremidades.

As sementes foram pré-tratadas com fungicida carboxin + thiran na dose de $0,5+0,5 \mathrm{~g}^{\mathrm{kg}} \mathrm{kg}^{-1}$ de semente e depois inoculadas antes da semeadura com 5 g. kg ${ }^{-1}$ de semente de inoculante turfoso, a uma densidade de $10^{9}$ células. $\mathrm{g}^{-1}$ de turfa. A semeadura, com a cultivar Carioca Precoce, foi realizada manualmente na primeira semana do mês de março com média de quinze sementes por metro linear. 
Na semeadura, todos os tratamentos foram adubados com 120 kg.ha ${ }^{-1}$ de $\mathrm{P}_{2} \mathrm{O}_{5}$ e 30 kg.ha ${ }^{-1}$ de $\mathrm{K}_{2} \mathrm{O}$, aplicados como superfosfato simples e cloreto de potássio, respectivamente. A adubaçáo nitrogenada foi realizada com uréia, aplicando $10 \mathrm{~kg} \cdot \mathrm{ha}^{-1} \mathrm{de} \mathrm{N}$ na semeadura e $50 \mathrm{~kg}$ ha $^{-1} \mathrm{em}$ cobertura quando as plantas atingiram o estádio $\mathrm{V}_{4}$ (quinta folha trifoliolada em mais de $50 \%$ das plantas). Nessa época, uma adubação potássica adicional de cobertura na dose de $30 \mathrm{~kg} \cdot \mathrm{ha}^{-1}$ de $\mathrm{K}_{2} \mathrm{O}$ foi realizada em todas as parcelas. No aparecimento das primeiras flores, foi aplicado por pulverização foliar $60 \mathrm{~g} \mathrm{ha}^{-1}$ de Mo na forma de molibdato de amônia.

Quando necessário, o controle de pragas e doenças foi feito com a aplicação dos inseticidas parathion-methyl (300 g.ha ${ }^{-1}$ e de chlorpirifos ( 400 g.ha ${ }^{-1}$ ), e fungicidas azoxistrobina $\left(50\right.$ g.ha $\left.^{-1}\right)$ e tebuconazole (150 g.ha $\left.{ }^{-1}\right)$. Ao longo do estudo, foram registrados problemas com as pragas Diabrotica speciosa e Cerotoma spp. (vaquinhas), bem como problemas fitopatológicos com Thanatephorus cucumeris (mela do feijoeiro). Todas as pulverizaçôes foram feitas com pulverizador costal, utilizando $200{\mathrm{~L} . h a^{-1}}$ de volume de calda.

Quando as parcelas apresentaram plantas com mais de 50\% de flores abertas, foram avaliadas as seguintes variáveis: número e massa de nódulos por planta, massa seca da parte aérea e raiz de três plantas coletadas ao acaso na parcela. Os feijoeiros foram retirados do solo e imediatamente imersos em recipiente contendo água para lavagem das raízes; posteriormente, a raiz foi cortada para quantificação dos nódulos. Folhas e ramos foram lavados e secos em estufa de ventilação forçada (temperatura de $65^{\circ} \mathrm{C}$ ), até atingir massa constante. Os nódulos, após serem quantificados, também foram colocados em estufa. Nessa fase, também foi avaliado o teor de $\mathrm{N}$ foliar, utilizando a última folha trifoliolada completamente expandida de dez plantas coletadas ao acaso na parcela. Estas foram devidamente secas pelo mesmo procedimento citado anteriormente, e após, encaminhadas para o laboratório para análise foliar, conforme o método de digestáo sulfúrica seguida de destilação Kjeldahl (EMBRAPA, 1997).

A colheita foi realizada manualmente após a maturaçáo fisiológica, que ocorreu aos 64 dias após a emergência. A trilha das parcelas experimentais foi com o uso de debulhador acoplado ao trator. Durante a colheita, foram determinadas as seguintes variáveis: número de vagens por planta e a altura de plantas, quinze plantas colhidas aleatoriamente, número de grãos por vagens amostradas em cinqüenta vagens, massa de cem grãos em duplicatas e rendimento de grãos da área útil convertido para kg.ha-1 ${ }^{-1}$ a $13 \%$ de umidade.

Os resultados foram submetidos à análise de variância e no caso do teste $\mathrm{F}$ significativo, as médias foram comparadas pelo teste de Tukey $(\mathrm{p}<0,05)$.

\section{RESULTADOS E DISCUSSÃO}

Entre os fatores principais foram verificados efeitos da adubação nitrogenada sobre a massa seca da parte aérea e altura de plantas (Tabela 1). Foram observadas interaçóes entre a adubação nitrogenada e a inoculaçấo de sementes para o número de nódulos por planta, a massa seca de nódulos e o rendimento de grãos (Tabela 2). A interação entre as adubações nitrogenada e molíbdica influenciou somente a massa de grãos (Tabela 3). As variáveis teor de $\mathrm{N}$ foliar e número de grãos por vagem foram afetadas pela interação entre a inoculação de sementes e as adubaçōes nitrogenada e molíbdica (Tabela 4). De maneira contrária, não foram observados efeitos significativos dos tratamentos sobre a massa seca de raízes e número de vagens por planta.

A adubação nitrogenada resultou em feijoeiros mais altos, com massa seca da parte aérea $23 \%$ superior à massa encontrada na ausência de $\mathrm{N}$ mineral (Tabela 1). Romanini Junior et al. (2007) também observaram incrementos na massa seca da parte aérea de feijoeiros com o uso do $\mathrm{N}$ mineral, porém não constataram efeito significativo da inoculação de sementes. Estes resultados confirmam que a aplicação do adubo nitrogenado no solo é facilmente absorvida pelo sistema radicular do feijoeiro, melhorando seu crescimento e acúmulo de massa seca.

Para a massa seca de raiz, não foi verificado efeito de tratamentos, apresentando média geral de 0,68 g.planta ${ }^{-1}$. Esse

Tabela 1 - Massa seca da parte aérea (MSPA) (A) e altura de plantas (B) de feijoeiros avaliadas no florescimento e colheita respectivamente em função da adubação nitrogenada. Rolim de Moura - R0, 2007

\begin{tabular}{|c|c|c|c|c|c|c|}
\hline \multirow[b]{2}{*}{$\mathrm{N}$} & \multicolumn{3}{|c|}{ MSPA (g) } & \multicolumn{3}{|c|}{ Altura de plantas $(\mathrm{cm})$} \\
\hline & $\begin{array}{c}\text { Sem } \\
\text { inoculante }\end{array}$ & $\begin{array}{c}\text { Com } \\
\text { inoculante }\end{array}$ & Média & $\begin{array}{c}\text { Sem } \\
\text { inoculante }\end{array}$ & $\begin{array}{c}\text { Com } \\
\text { inoculante }\end{array}$ & Média \\
\hline Sem N & 5,90 & 6,04 & $5,97 \mathrm{~B}$ & 46,11 & 46,48 & $46,29 \mathrm{~B}$ \\
\hline Com N & 8,26 & 7,06 & $7,66 \mathrm{~A}$ & 47,89 & 48,37 & $48,13 \mathrm{~A}$ \\
\hline CV (\%) & \multicolumn{3}{|c|}{11,97} & \multicolumn{3}{|c|}{6,29} \\
\hline
\end{tabular}

Médias seguidas pela mesma letra não diferem entre si pelo teste de Tukey $(p<, 0,05)$. 
Tabela 2 - Número de nódulos, massa seca de nódulos e rendimento de grãos encontrados no feijoeiro em função da adubação nitrogenada e da inoculação de sementes com Rhizobium tropicci. Rolim de Moura - R0, 2007

\begin{tabular}{|c|c|c|c|c|c|c|}
\hline \multirow{2}{*}{$\mathrm{N}$} & \multicolumn{2}{|c|}{ Número de nódulos } & \multicolumn{2}{|c|}{ Massa de nódulos (g) } & \multicolumn{2}{|c|}{ Rendimento de grãos $\left(\mathrm{kg} \mathrm{ha}^{-1}\right)$} \\
\hline & $\begin{array}{c}\text { Sem } \\
\text { inoculante }\end{array}$ & Com inoculante & $\begin{array}{c}\text { Sem } \\
\text { inoculante }\end{array}$ & $\begin{array}{c}\text { Com } \\
\text { inoculante }\end{array}$ & $\begin{array}{c}\text { Sem } \\
\text { inoculante }\end{array}$ & $\begin{array}{c}\text { Com } \\
\text { inoculante }\end{array}$ \\
\hline Sem N & $95,79 \mathrm{~A} \mathrm{~b}$ & $271,46 \mathrm{~A} \mathrm{a}$ & $0,11 \mathrm{Ab}$ & $0,19 \mathrm{~A} \mathrm{a}$ & $909,62 \mathrm{~B} \mathrm{a}$ & $1059,62 \mathrm{~A} \mathrm{a}$ \\
\hline Com N & $55,58 \mathrm{~B} \mathrm{a}$ & $79,17 \mathrm{~B} \mathrm{a}$ & $0,06 \mathrm{~B} \mathrm{a}$ & $0,07 \mathrm{~B} \mathrm{a}$ & $1072,49 \mathrm{~A} \mathrm{a}$ & $1011,04 \mathrm{~A} a$ \\
\hline CV (\%) & & & & & & \\
\hline
\end{tabular}

Médias seguidas pela mesma letra, maiúscula na vertical e minúsculas na horizontal, não diferem entre si pelo teste de Tukey $(\mathrm{p}<, 0,05)$.

Tabela 3 - Massa de cem grãos de feijão em função das adubações nitrogenada e molibdica. Rolim de Moura - R0, 2007

\begin{tabular}{lcc}
\hline & Sem N & Com N \\
\hline Sem molibdênio & $22,50 \mathrm{~A} \mathrm{~b}$ & $25,50 \mathrm{~A} \mathrm{a}$ \\
Com molibdênio & $22,56 \mathrm{~A} \mathrm{a}$ & $22,40 \mathrm{~B} \mathrm{a}$ \\
CV (\%) & & \\
\hline
\end{tabular}

Médias seguidas pela mesma letra, maiúscula na vertical e minúsculas na horizontal, não diferem entre si pelo teste de Tukey $(\mathrm{p}<, 0,05)$. resultado difere de Carvalho (2002), que encontrou correlaçáo significativa entre as massas secas de raiz e da parte aérea do feijoeiro.

O desdobramento da interação entre a adubação nitrogenada e a inoculação de sementes apresentou comportamento semelhante para o número de nódulos por planta, a massa seca dos nódulos e o rendimento de gráos (Tabela 2). A adubação nitrogenada reduziu o número e a massa seca dos nódulos, mesmo nos tratamentos inoculados. Entretanto, na ausência da adubaçáo nitrogenada, a inoculaçáo de sementes proporcionou aumentos de $388 \%$ e $217 \%$ no número e massa seca de nódulos, respectivamente, em relação à menor média observada.

Tabela 4 - Teor de N nas folhas do feijoeiro e número de grãos por vagem em função da adubação molibdica e da inoculação de sementes do feijoeiro, na ausência e presença da adubação nitrogenada. Rolim de Moura - R0, 2007

\begin{tabular}{|c|c|c|c|c|}
\hline \multirow{3}{*}{$\begin{array}{l}\text { Inoculação } \\
\text { de sementes }\end{array}$} & \multicolumn{4}{|c|}{ Teor de N foliar (\%) } \\
\hline & \multicolumn{2}{|c|}{ Sem N } & \multicolumn{2}{|c|}{ Com N } \\
\hline & Sem Mo & Com Mo & Sem Mo & Com Mo \\
\hline Sem inoculação & $3,00 \mathrm{~A} \mathrm{a}$ & $2,67 \mathrm{~B} \mathrm{a}$ & $2,75 \mathrm{~A} \mathrm{a}$ & $2,87 \mathrm{~A} \mathrm{a}$ \\
\hline Inoculado & $2,67 \mathrm{~A} \mathrm{~b}$ & $3,27 \mathrm{~A} \mathrm{a}$ & $2,55 \mathrm{~A} \mathrm{a}$ & $2,56 \mathrm{~A} \mathrm{a}$ \\
\hline CV (\%) & \multicolumn{4}{|c|}{7,92} \\
\hline \multirow{3}{*}{$\begin{array}{l}\text { Inoculação } \\
\text { de sementes }\end{array}$} & \multicolumn{4}{|c|}{ Número de grãos por vagem } \\
\hline & \multicolumn{2}{|c|}{ Sem N } & \multicolumn{2}{|c|}{ Com N } \\
\hline & Sem Mo & Com Mo & Sem Mo & Com Mo \\
\hline Sem inoculação & $3,18 \mathrm{~A} \mathrm{a}$ & $3,76 \mathrm{~A} \mathrm{a}$ & $3,16 \mathrm{~A} \mathrm{a}$ & $3,04 \mathrm{~A} \mathrm{a}$ \\
\hline Inoculado & $3,24 \mathrm{~A} \mathrm{a}$ & $2,93 \mathrm{~B} \mathrm{a}$ & $2,58 \mathrm{Ab}$ & $3,35 \mathrm{~A} \mathrm{a}$ \\
\hline CV (\%) & & & & \\
\hline
\end{tabular}

Médias seguidas pela mesma letra, maiúscula na vertical e minúsculas na horizontal, não diferem entre si pelo teste de Tukey $(\mathrm{p}<, 0,05)$. 
Desse modo, ficou evidente o efeito negativo do $\mathrm{N}$ fornecido pela adubação. Entretanto, pode-se observar que nos tratamentos que não receberam inoculação houve nodulação, mesmo que em quantidades inferiores, podendose sugerir a presença de estirpes nativas no solo nodulando os feijoeiros, e que o aumento no número de nódulos encontrado nos tratamentos inoculados pode ser atribuído ao efeito da inoculação. Fullin et al. (1999) e Vieira et al. (2005) também verificaram a presença de populaçáo nativa de rizóbios em solos, nodulando feijoeiros.

Os resultados referentes à nodulação confirmam os encontrados na literatura, conforme os quais quantidades mínimas de $\mathrm{N}$ são capazes de suprimir a nodulação e a atividade dos nódulos em feijoeiros (Ferreira et al., 2000; Carvalho, 2002; Venturini et al., 2005; Romanini Junior et al., 2007), pois na presença do nutriente náo ocorre o estímulo necessário à nodulação. Os valores observados nos tratamentos referente à inoculaçáo sem a presença de $\mathrm{N}$ ficaram acima dos encontrados por Souza et al. (2003), que registraram 166 nódulos.planta ${ }^{-1}$, quando compararam diferentes estirpes na nodulaçáo do feijoeiro. Porém, Carvalho (2002) ressalta, que nem sempre o maior número de nódulos implica em melhor aproveitamento da FBN pela planta, sugerindo que a elevada nodulação resulta em formação de nódulos menores, com menor eficiência relativa. Venturini $e t$ al. (2005) não evidenciaram diferença no número de nódulos, porém, verificaram redução na massa seca dos mesmos quando utilizaram vermicomposto como fonte de N. Segundo os autores, a nodulaçáo foi afetada a grande quantidade de nutrientes fornecida por esse fertilizante. Por outro lado, os resultados diferem dos encontrados por Fullin et al. (1999), que avaliando os efeitos do $\mathrm{N}$ e do $\mathrm{Mo}$ em feijoeiros não verificaram influência da adubaçáo nitrogenada sobre o número e massa seca de nódulos.

A utilizaçáo em conjunto das duas fontes de $\mathrm{N}$, ou seja, adubação nitrogenada e inoculação de sementes, produziu rendimento de grãos semelhante a aquelas em que utilizou apenas uma fonte; porém, na ausência da adubação nitrogenada e da inoculação de sementes, verificou-se redução no rendimento de grãos (Tabela 2). Dessa forma, ficou evidente a importância da disponibilização de $\mathrm{N}$ ao feijoeiro, uma vez que tanto as condiçóes de fertilidade natural do solo como as estirpes nativas de rizóbio não foram suficientes para garantir produtividade máxima. Apesar disso, os resultados indicam boa eficiência das estirpes inoculadas quanto à FBN se comparado aos efeitos do $\mathrm{N}$ fornecido pela adubação mineral. Todavia, quando o $\mathrm{N}$ é fornecido via adubação, a planta não respondeu ao estímulo necessário à nodulação (Tabela 2).

Araújo et al. (1996) e Lemos et al. (2003), avaliando a nodulaçáo em cultivares de feijāo reportaram que a cultivar Carioca Precoce apresentou melhor desempenho simbiótico em relação a outros cultivares, sendo provável que os resultados encontrados neste estudo estejam relacionadas também a cultivar utilizada. Corroborando, Soares et al. (2006) verificaram que a inoculação de sementes resultou em rendimentos de grãos semelhantes aos feijoeiros fertilizados com $70 \mathrm{~kg} \cdot \mathrm{ha}^{-1}$ de N. Similarmente, Romanini Junior et al. (2007) observaram aumentos na produtividade de feijoeiros com a inoculação de sementes.

O rendimento de grãos obtido neste estudo, embora maior do que a média nacional, é menor do que outros encontrados na literatura (Ferreira et al., 2000; Lemos et al., 2003; Nascimento et al., 2004; Santini et al., 2006). É possível que o resultado tenha sido afetado pelas altas temperaturas registradas no período de florescimento, ocasionando considerável abortamento de flores, conseqüentemente, afetando os componentes do rendimento. A alta temperatura e alta umidade relativa do ar, que normalmente ocorrem nessa região, predispôem a ocorrência de "mela do feijoeiro", que é uma doença comum em Rondônia, responsável por grandes perdas de produtividade (Souza et al, 2005).

Entre os componentes de rendimento do feijoeiro, a massa de cem grãos foi afetada pela interação Mo e N (Tabela 3), náo sendo constatado efeito da inoculação de sementes. Observou-se efeito positivo do $\mathrm{N}$ fornecido pela adubação mineral, uma vez que na presença deste e ausência de Mo houve aumento de $14 \%$ na massa de grãos em relação aos demais tratamentos. Por outro lado, quando não se utilizou $\mathrm{N}$, tanto na ausência como na presença de Mo foi registrada a mesma massa de grãos (Tabela 3). Todos os tratamentos apresentaram médias de massa de cem grãos dentro dos padrôes da cultivar (Souza et al., 2005).

$\mathrm{O}$ desdobramento das interaçóes para o teor de $\mathrm{N}$ foliar mostrou que na presença de $\mathrm{N}$, os demais tratamentos náo diferiram entre si; entretanto, na ausência de $\mathrm{N}$, foi verificado efeito positivo da combinaçáo de inoculação de sementes e Mo, resultando em maior acúmulo de $\mathrm{N}$ no tecido foliar (Tabela 4). Segundo Carvalho (2002) o maior número de nódulos náo resulta, necessariamente, em maior FBN, uma vez que o Mo não apresentou efeitos sobre número e massa seca de nódulos, mas foi eficiente no acúmulo de $\mathrm{N}$ pela planta, evidenciando sua participação no metabolismo.

Berger et al. (1996) constataram em duas cultivares de feijoeiro, que não foram fertilizadas com Mo, níveis de $\mathrm{N}$ foliar abaixo daquele considerado crítico, ao mesmo tempo em que foram observadas respostas lineares nos níveis de $\mathrm{N}$ com aumentos nas doses de Mo, demonstrando a importância do micronutriente no acúmulo de N pelo feijoeiro. Fernandes et al. (2005) comentam que a adubação nitrogenada proporciona plantas mais altas e com maior massa seca e, em conseqüência, devido ao efeito de diluiçáo de nutrientes, resultam em plantas com menores teores de $\mathrm{N}$ foliar. 
Os mesmos autores também evidenciaram maiores teores de $\mathrm{N}$ foliar em feijoeiros não adubados com este nutriente.

$\mathrm{O}$ número de vagem por planta não foi afetado pelos tratamentos, com média geral de sete vagens.planta ${ }^{-1}$. Por outro lado, a variável número de grãos por vagem sofreu efeito da interação entre inoculação de sementes, $\mathrm{N}$ e Mo das adubaçôes (Tabela 4). Na ausência de $\mathrm{N}$ mineral, o uso de Mo proporcionou maior número de grãos por vagem. Na presença de $\mathrm{N}$, a menor média foi obtida no tratamento inoculado sem a combinação com Mo. Assim, verifica-se que, apesar do Mo apresentar relativa importância para o incremento de grãos por vagem e para o teor de $\mathrm{N}$ foliar, não refletiu no rendimento de grãos. Este efeito vem corroborar os resultados encontrados por Ferreira et al. (2003), que reportara respostas do Mo no número de grãos por vagem, porém, sem influenciar no rendimento de gráos.

De forma geral, a adubação molíbdica apresentou pouco ou nenhum efeito sobre as variáveis avaliadas, discordando de resultados da literatura (Vieira et al., 2000; Bassan et al., 2001; Nascimento et al., 2004). Este comportamento pode estar associado ao $\mathrm{pH}$ do solo (POTAFÓS, 1996), a disponibilidade de Mo nas sementes de feijão (Jacob Neto \& Rossetto, 1998) e a dose utilizada, uma vez que Berger et al. (1996) encontraram maiores rendimentos de feijoeiros utilizando doses entre 80 e 90 g.ha ${ }^{-1}$.

\section{CONCLUSÕES}

A adubação nitrogenada reduziu a nodulação do feijoeiro;

A inoculação de sementes do feijoeiro proporcionou rendimentos de grãos compatíveis às obtidas pela adubação nitrogenada;

A adubação molibdica proporcionou os maiores teores de $\mathrm{N}$ foliar e número de grãos por vagem, porém, não afetou o rendimento de grãos.

\section{BIBLIOGRAFIA CITADA}

Araújo, F.F.; Munhoz, R.V.; Hungria, M. 1996. Início da nodulação em sete cultivares de feijoeiro inoculadas com duas estirpes de Rhizobium. Pesquisa Agropecuária Brasileira, 31 (6): 435-443.

Bassan, D.A.Z.; Arf, O.; Buzetti, S., Carvalho, M.A.C.C.; Santos, N.C.B.; Sá, M.E. 2001. Inoculação de sementes e aplicação de nitrogênio e molibdênio na cultura do feijão de inverno: produção e qualidade fisiológica de sementes. Revista Brasileira de Sementes, 23 (1): 76-83.

Berger, P.G.; Vieira, C.; Araújo, G.A.A. 1996. Efeito de doses e épocas de aplicação do molibdênio sobre a cultura do feijão. Pesquisa Agropecuária Brasileira, 31 (7): 473-480.

Carvalho, E.A. 2002. Avaliação agronômica da disponibilização de nitrogênio à cultura de feijão sob sistema de semeadura direta. Tese de Doutorado, Escola Superior de Agricultura "Luiz de Queiroz”, Piracicaba, São Paulo, 80pp.
EMBRAPA. Centro Nacional de Pesquisa de Solos. 1997. Manual de métodos de análise de solos. 2 ed. rev. e atual. Rio de Janeiro: EMBRAPA, 212pp.

Fernandes, F.A.; Arf, O.; Binotti, F.F.S.; Romanini Junior, A.; Sá, M.E.; Buzetti, S.; Rodrigues, R.A.F. 2005. Molibdênio foliar e nitrogênio em feijoeiro cultivado no sistema plantio direto. Acta Scientiarum, 27 (1): 7-15.

Ferreira, A.N.; Arf, O.; Carvalho, M.A.C.; Araújo, R.S.; Sá, M.E.; Buzetti, S. 2000. Estirpes de Rhizobium tropici na inoculação do feijoeiro. Scientia Agricola, 57 (3): 507-512.

Ferreira, A.C.B.; Araújo, G.A.A.; Cardoso, A.A.; Rezende, P.C.; Fontes, P.C.R.; Vieira, C. 2003. Características agronômicas do feijoeiro em funçáo do molibdênio contido na semente e da sua aplicação via foliar. Acta Scientiarum, 25 (1): 65-72.

Fullin, E.A.; Zangrande, M.B.; Lani, J.A.; Mendonça, L.F.; Filho, N.D. 1999. Nitrogênio e molibdênio na adubação do feijoeiro irrigado. Pesquisa Agropecuária Brasileira, 34 (7): 1145-1149.

Hungria, M.; Campo, R.J.; Mendes, I.C. 2001. Fixação biológica de nitrogênio na cultura da soja. Embrapa soja: Circular técnica 35. Londrina, Paraná. 48 pp.

IBGE - Instituto Brasileiro de Geografia e estatística. 2008. Lavouras: Produção de cereais, leguminosas e oleaginosas (www. ibge.gov.br/home/estatistica/indicadores/agropecuaria/lspa/ 1spa_200803comentarios.pdf.). Acesso: 12/03/2008.

Jacob-Neto, J.; Rossetto, C.A.V. 1998. Concentração de nutrientes nas sementes: o papel do molibdênio. Floresta e Ambiente, 5(1): 171-183.

Lemos, L.B.; Fornasieri Filho, D.; Camargo, M.B.; Silva, T.R.B.; Soratto, R.P. 2003. Inoculação de rizóbio e adubaçáo nitrogenada em genótipos de feijoeiro. Agronomia, 37 (1): 26 - 31.

Malavolta, E. 2006. Manual de nutrição Mineral de plantas. São Paulo: Editora Agronômica Ceres, 638pp.

Marialva, V.G. 1999. Diagnóstico Socioeconômico: Ji-Paraná. Porto Velho: SEBRAE-RO.

Mendes, I.C.; Suhet, A.R.; Peres, J.R.R.; Vargas, M.A.T. 1994. Eficiência fixadora de estirpes de rizóbio em duas cultivares de feijoeiro. Revista Brasileira Ciência Solo, 18 (3): 421 - 425.

Nascimento, M.S.; Arf, O.; Silva, M.G. 2004. Resposta do feijoeiro à aplicaçáo de nitrogênio em cobertura e molibdênio via foliar. Acta Scientiarum, 26 (2): 153-159.

Oliveira, I.P.; Araújo, R.S.; Dutra; L.G. 1996. Nutrição mineral e fixação biológica de nitrogênio. In.: Araujo, R.S.; Rava, C.A.; Stone, L.F.; Zimmermann, M.J.O (Eds). Cultura do feijoeiro comum do Brasil. Piracicaba: POTAFÓS. p 169-221.

Pereira, J.C.; Vidor, C.; Lovato, P.E.; Penteado, A.F. 1991. Simbiose entre feijão e estirpes de Rhizobium leguminosarum bv. Phaseoli, sensíveis e resistentes a antibióticos e fungicidas. Pesquisa Agropecuária Brasileira, 26 (7):1097-1105.

POTAFÓS. 1996. Informação agronômica sobre nutrientes para as culturas. Arquivo do Agrônomo, 10: 12 p.

Romanini Junior, A.; Arf. O.; Binotti, F.F.S.; Sá, M.E.; Buzetti, S.; Fernandes, F.A. 2007. Avaliação da inoculação de rizóbio e adubação nitrogenada no desenvolvimento do feijoeiro, sob sistema plantio direto. Bioscience Journal, 23 (4): 74-82. 
Santini, A.L.; Dutra, L.M.C.; Martin, T.N.; Bellé, G.L.; Bonadiman, R.; Della Flora, L.P.; Jauer, A. 2006. Adubaçáo nitrogenada na cultura do feijoeiro em plantio convencional. Ciência Rural, 36 (4): 1079-1085.

Soares, A.A.L.; Ferreira, P.A.A.; Pereira, J.P.A.R.; Vale, H.M.M; Lima, A.S.; Andrade, M.J.B.; Moreira, F.M.S. 2006. Eficiência agronômica de rizóbios selecionados e diversidade de populaçôes nativas nodulíferas em Perdóes (MG): II Feijoeiro. Revista Brasileira Ciência Solo, 30 (5): 803-811.

Soratto, R.P.; Carvalho, M.A.C.; Arf, O. 2006. Nitrogênio em cobertura no feijoeiro cultivado em plantio direto. Revista Brasileira Ciência Solo, 30 (2): 259-265.

Souza, F.F.; Ramalho, A.R.; Nunes, A.M.L. 2005. Cultivo do feijāo comum em Rondônia. Embrapa Rondônia: Sistema de Produção 8. Porto Velho, Rondônia (http://sistemasdeproducao.cnptia. embrapa.br). Acesso: 10/05/2007.

Souza, M.F.M.; Vale H.M.M.; Straliotto, R. 2003. Competitividade de estirpes pertencentes a diferentes espécies de rizóbio para ocupação nodular em feijoeiro (Phaseolus vulgaris L.). Agronomia, 37 (1): $59-63$.
Straliotto, R.; Teixeira, M.G. A. 2000. Variabilidade Genética do Feijoeiro (Phaseolus vulgaris L.L): aplicaçôes nos estudos das interações simbióticas e patogênicas. Seropédica: Embrapa Agrobiologia, 59p. (Embrapa-Agrobiologia. Documentos, 126)

Venturini, S.F; Antoniolli, Z.I.; Steffen, R.B.; Venturini, E.F; Giracca, E.M.N. 2005. Efeito do vermicomposto, uréia e inoculação com Rhizobium phaseoli na cultura do feijão. Revista de Ciências Agroveterinárias, 4 (1): 52-59.

Vieira, C.; Paúla Junior, T.J.; Borém, A. 1998. Feijão: aspectos gerais e cultura no estado de Minas Gerais. Universidade Federal de Viçosa: Minas Gerais, 596 pp.

Vieira, R.F.; Tsai, S.M.; Teixeira, M.A. 2005. Nodulação e fixação simbiótica de nitrogênio em feijoeiro com estirpes nativas de rizóbio, em solo tratado com lodo de esgoto. Pesquisa Agropecuária Brasileira, 40 (10): 1047-1050.

Vieira, S.M.; Ronzelli Junior, P.; Daros, E.; Koehler, H.S. Prevedello, B.M.S. 2000. Nitrogênio, molibdênio e inoculante para a cultura do feijoeiro. Scientia Agraria, 1 (1-2): 63-66.

Recebido em 10/05/2008

Aceito em 26/08/2009 
